\title{
Epigenetic therapy: use of agents targeting deacetylation and methylation in cancer management
}

This article was published in the following Dove Press journal:

OncoTargets and Therapy

20 March 2013

Number of times this article has been viewed

\author{
Allen $\mathrm{S} \mathrm{Ho}$ \\ Sevin Turcan' \\ Timothy A Chan ${ }^{1,2}$ \\ 'Human Oncology and Pathogenesis \\ Program, Memorial Sloan-Kettering \\ Cancer Center, New York, NY, \\ USA; ${ }^{2}$ Brain Tumor Center, Memorial \\ Sloan-Kettering Cancer Center, \\ New York, NY, USA
}

\begin{abstract}
The emergence of epigenetic mechanisms as key regulators of gene expression has led to dramatic advances in understanding cancer biology. Driven by complex layers that include aberrant DNA methylation and histone modification, epigenetic aberrations have emerged as critical processes that disrupt cellular machinery and homeostasis. Recent discoveries have already translated into successful clinical trials and improved patient care, with several agents approved for hematologic disease and others undergoing study. As the field matures, substantial challenges persist that will require resolution. These include the need to decipher more fully the interplay between the epigenetic and genetic machinery, patient selection and improving treatment efficacy in solid tumors, and optimizing combination therapies to counteract chemoresistance and minimize adverse effects. Here, we review recent progress in epigenetic treatments and consider their implications for future cancer therapy.
\end{abstract}

Keywords: epigenetics, cancer, acetylation, methylation, histone, transcription, tumor

\section{Introduction}

The field of epigenetics comprises a wide range of reversible modifications that orchestrate gene expression. The genome is organized into relaxed euchromatin and condensed heterochromatin, and DNA is interlaced among histones, which are in turn post-translationally altered to enable or disable transcription. The relative structural simplicity of DNA is therefore supported by immense modulation from epigenetic factors that are both tissue- and context-specific. It is these factors that enable a broad range of phenotypes to be manifested from a common DNA blueprint.

Advances in deciphering the fundamental machinery of the epigenome have led to significant insights into cell physiology as well as oncogenesis. This information has provided a fuller and more nuanced understanding of epigenetic abnormalities linked to genetic mutations, including the roles of methylation and acetylation. Although these marks are somatically heritable, the fact that they are also reversible suggests exciting implications for therapy. Defining (and restoring) the "normal" epigenetic landscape has consequently been the focus of active investigation, and has already generated breakthroughs in cancer detection, treatment, and prognosis. Swift approval of epigenetically targeted drugs by the US Food and Drug Administration (FDA) for hematologic conditions has cemented its role in the clinical sphere ${ }^{1-4}$ (Table 1), and many phase II and III clinical trials are under way for multiple conditions, including solid malignancies. ${ }^{5-7}$ Below, we highlight the interface between the genome and epigenome and examine the clinical impact facilitated by current and future epigenetic agents. 
Table I Examples of approved epigenetic agents

\begin{tabular}{|c|c|c|c|c|c|c|c|}
\hline Agent & Class & $\begin{array}{l}\text { Disease } \\
\text { indications }\end{array}$ & $\begin{array}{l}\text { FDA } \\
\text { approval } \\
\text { data }\end{array}$ & $\begin{array}{l}\text { Main study } \\
\text { institution }\end{array}$ & $\begin{array}{l}\text { Number } \\
\text { of patients }\end{array}$ & Basis of approval & Side effects \\
\hline 5-azacitidine & $\begin{array}{l}\text { DNMT } \\
\text { inhibitor }\end{array}$ & MDS & 2004 & $\begin{array}{l}\text { Memorial } \\
\text { Sloan-Kettering; } \\
\text { Mount Sinai }\end{array}$ & 191 & $\begin{array}{l}\text { Phase III trial; } 23 \% \text { response rate; } \\
\text { significantly improved median } \\
\text { survival compared to supportive } \\
\text { care (I } 8 \text { months vs II months) }\end{array}$ & $\begin{array}{l}\text { Myelosuppression } \\
\text { (thrombocytopenia, } \\
\text { neutropenia, anemia) }\end{array}$ \\
\hline Decitabine & $\begin{array}{l}\text { DNMT } \\
\text { inhibitor }\end{array}$ & MDS & 2006 & MD Anderson & 170 & $\begin{array}{l}\text { Phase III trial; I } 7 \% \text { response rate; } \\
\text { trend toward improved median } \\
\text { survival compared to supportive } \\
\text { care (I } 2 \text { months vs } 8 \text { months) }\end{array}$ & $\begin{array}{l}\text { Myelosuppression } \\
\text { (thrombocytopenia, } \\
\text { neutropenia, anemia) }\end{array}$ \\
\hline Vorinostat & $\begin{array}{l}\text { HDAC } \\
\text { inhibitor }\end{array}$ & CTCL & 2006 & Duke & 74 & $\begin{array}{l}\text { Phase IIB trial; } 30 \% \text { response rate; } \\
\text { median time to progression was } \\
5 \text { months }\end{array}$ & $\begin{array}{l}\text { Diarrhea, fatigue, } \\
\text { nausea, anorexia }\end{array}$ \\
\hline Romidepsin & $\begin{array}{l}\text { HDAC } \\
\text { inhibitor }\end{array}$ & CTCL & 2009 & $\begin{array}{l}\text { National Institutes } \\
\text { of Health; King's } \\
\text { College London }\end{array}$ & $167(96+7 I)$ & $\begin{array}{l}\text { Phase II trails; } 34 \%-38 \% \text { response } \\
\text { rates; median response duration } \\
\text { was II-I5 months }\end{array}$ & $\begin{array}{l}\text { Nausea, fatigue, anemia, } \\
\text { thrombocytopenia, } \\
\text { ECG T- wave changes, } \\
\text { neutropenia, } \\
\text { and lymphopenia }\end{array}$ \\
\hline
\end{tabular}

Abbreviations: DNMT, DNA methyltransferase; HDAC, histone deacetylase; MDS, myelodysplastic syndrome; CTCL, cutaneous T-cell lymphoma.

\section{DNA methylation and histone modification}

Two of the most common types of epigenetic alterations in cancer involve aberrant changes in DNA methylation and histone modification. These alterations occur at multiple layers of regulation, directing gene expression via maintenance of restricted and permissive chromatin states. Such regulators can also be commandeered by cancer cells for oncogenic gain. ${ }^{8}$ Methylation consists of the addition of a methyl group to the $5^{\prime}$ position of the cytosine ring in $\mathrm{CpG}$ dinucleotides (5 mc) and typically occurs in $\mathrm{CpG}$ islands within promoter regions. DNA hypermethylation in promoters can lead to the silencing of gene expression. Other areas found to harbor $\mathrm{CpG}$ methylation include vast areas in the genome with repetitive sequence, such as centromeres and transposon elements (involved in chromosomal stability), ${ }^{9}$ $\mathrm{CpG}$ island shores, ${ }^{10}$ noncoding regions (ie, enhancer regions and miRNAs), ${ }^{11}$ and gene bodies (silencing alternative transcription start sites). ${ }^{12}$ Approximately $60 \%$ of gene promoters contain $\mathrm{CpG}$ sites. ${ }^{13}$

The central workhorse molecules that lay down DNA methylation are the DNA methyltransferases. As a maintenance enzyme, DNMT1 preserves existing methylation patterns after cell replication, and its deletion leads to apoptosis ${ }^{13}$ as well as death in mice if lost during embryonic development. ${ }^{14}$ In contrast, DNMT3 A and -3B are de novo methyltransferases that methylate previously unmethylated DNA. While they are in the same general class of enzymes and share similarities within their catalytic domains, their roles in tumorigenesis may differ: DNMT3A deletion may promote cancer progression, ${ }^{15}$ yet DNMT3B deletion may in fact inhibit oncogenesis by liberating previously silenced tumor-suppressor genes. ${ }^{16,17}$ Interestingly, a substantial degree of DNA methylation in embryonic stem cells appears to occur independently of $\mathrm{CpG}$ sites ${ }^{18}$ and the Ten-Eleven-Translocation (TET) oxidase family has been reported to convert 5-methylcytosine to 5-hydroxymethylcytosine as a step toward demethylation, a process that does not seem to be restricted to $\mathrm{CpG}$ islands. ${ }^{19}$ The exact roles of these phenomena in epigenetic regulation remain to be elucidated.

Besides direct manipulation of DNA, modification of the core histones (ie, two copies of H2A, H2B, H3, and $\mathrm{H} 4$ proteins) also play important roles in epigenetic regulation. These histones selectively bind and release DNA as nucleosomes to moderate transcription, a process that is regulated through the addition of acetyl, methyl, phosphoryl, ubiquityl, or sumoyl groups, producing a dynamic epigenetic histone code (Figure 1).$^{20}$ These histone marks are deposited or removed by a plethora of proteins and clinical targets, including histone acetyltransferases (HATs), histone deacetylases (HDACs), histone methyltransferases (HMTs), histone demethylases (HDMs), kinases, phosphatases, and others. Here, we will summarize some salient parts of this biology, and for greater detail, the reader is directed to a couple of excellent reviews on these processes. ${ }^{21,22}$ Acetylation of lysines at specific sites (such as on H3K4, etc) by HATs negates the positive histone charge, permitting 


\section{A}

Transcription activated
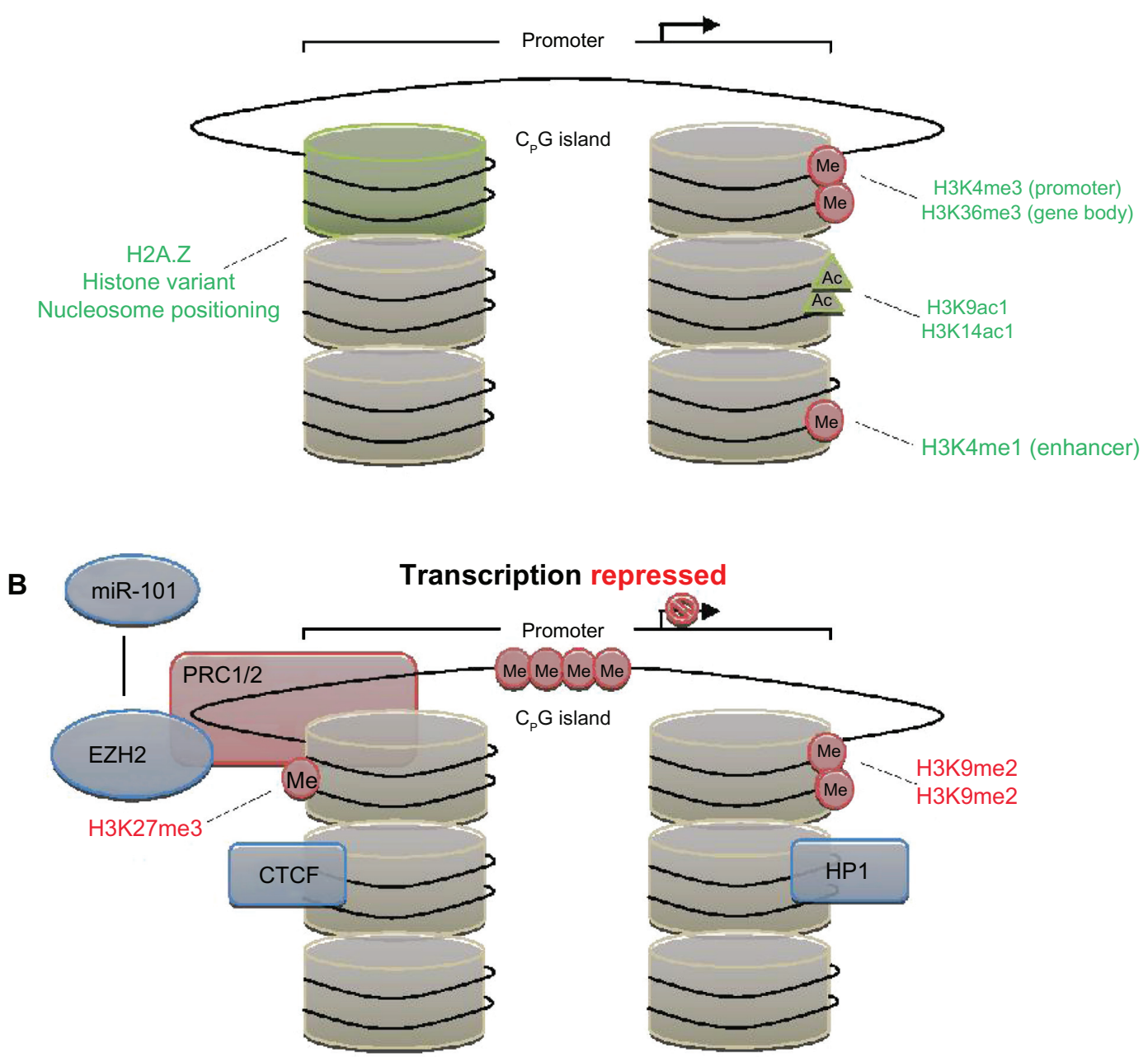

Figure I (A and B) Epigenetic mechanisms of transcriptional regulation. (A) Transcriptional activation, and (B) transcriptional repression with associated histone marks. Abbreviations: $\mathrm{EZH} 2$, enhancer of zeste 2; PRCI/2, polycomb repressive complex I/2; CTCF, CCCTC-binding factor; Me, methylation mark; Ac, acetylation mark.

negatively charged DNA to take on a transcription-ready configuration. HDACs, however, remove acetyl groups from histones, causing the oppositely charged histone to bind DNA and shield it from expression. While there are exceptions to each generality, DNA methylation typically silences gene expression, while histone marks can activate or silence genes, depending on the target residues, the targeted histone and extent of the alteration. ${ }^{23}$

Histone marks work together. Numerous histone modifications are now known to synergize in a combinatorial way, establishing specific states to activate or inhibit expression. Permissive chromatin states, for instance, are established by histone $\mathrm{H} 3$ marks such as trimethylation of lysine (K) 4 over the promoter and K36 over the gene body (H3K4me3 and H3K36me3, respectively). ${ }^{24,25}$ Other enabling marks include monoacetylation of $\mathrm{H} 3 \mathrm{~K} 9$ and H3K14 (H3K9ac1 and H3K14ac1), ${ }^{26}$ the presence of variant histones such as H2A.Z, ${ }^{27}$ and methylation of enhancer elements downstream (H3K4me1). ${ }^{28}$ Nucleosome positioning represents an additional contributory layer, and is determined by the intrinsic binding affinity of the DNA sequence, competitive binding of surrounding proteins, and translocation activity by adenosine triphosphate-dependent remodeling complexes. ${ }^{29}$

Conversely, heterochromatin configurations that compact nucleosomes are classically indicated by $\mathrm{H} 3 \mathrm{~K} 27 \mathrm{me} 3$, $\mathrm{H} 3 \mathrm{~K} 9 \mathrm{me} 3$, and $\mathrm{H} 3 \mathrm{~K} 9 \mathrm{me} 2,{ }^{30}$ as well as the presence of inhibitory proteins such as CTCF and HP1. ${ }^{31,32}$ This is in addition to dense, localized DNA methylation. Repression can be initiated by the Polycomb group (Polycomb repression complex $[\mathrm{PRC}]$ ) proteins, which methylate the histones in promoter regions. ${ }^{33}$ Such $\mathrm{PRC}$ regulators, including enhancer of zeste 2 (EZH2), ${ }^{34}$ are themselves regulated by noncoding RNAs such as miRNA-101 to inhibit expression. ${ }^{35,36}$ 
Collectively, such interplay between systems previously thought to be independent underscores the overarching importance of the epigenome in coordinating transcription, and of course downstream biological events. Its complexity gives rise to enormously flexible conditions that guide development and physiology, but can also be readily misappropriated for disease states such as tumorigenesis.

\section{Epigenetic mechanisms of transcription regulation in cancer}

Epigenetic dysregulation in malignant cells can be generalized across cancer types, and is characterized by global hypomethylation and focal hypermethylation. ${ }^{37}$ These events occur early on in tumorigenesis, including in early stage and in situ lesions, ${ }^{38}$ suggesting that these changes help establish an advantageous milieu for cancer formation. Such broad hypomethylation has been shown to induce genomic instability by activating normally quiet transcription start sites and transposon activity (increasing the likelihood of structural variation), ${ }^{20,37}$ while aberrantly methylated promoter areas silence key tumor suppressors. Similar studies have reported decreased acetylation from overexpressed HDACs and inhibited HATs (eg, H4K16ac1), ${ }^{39}$ as well as dysregulated histone methylation (eg, H4K20me3). ${ }^{40}$ Together with genetic mutations, epigenetic changes can engender favorable environments for tumorigenesis and resistance to therapy. Moreover, epigenetic alterations leading to cancer are not limited to just direct change of gene function, but also predispose to genetic mutation or dysregulation of entire signaling pathways and DNA integrity. ${ }^{41}$ Genetic driver mutations affecting epigenetic players such as DNMT3A, UTX, etc ${ }^{42}$ have been reported to be quite frequent events. ${ }^{43}$

Aberrant promoter hypermethylation is a hallmark of cancer and is one of the most common alterations seen in malignancies. VHL1 (renal carcinoma), BRCA1 (breast cancer), and RB1 are examples of classic tumor suppressors whose dysregulation can result from either mutation or epigenetic silencing via hypermethylation. ${ }^{44}$ Other tumor suppressors that are mutated (ie, CDKN2A, encoding INK4A) can instead be inactivated by epigenetic silencing. ${ }^{45,46}$ This was first seen years ago in a number of ad hoc analyses on candidate cancer genes. ${ }^{47}$ These findings have been confirmed through high-throughput, global analyses of cancer genomes and epigenomes, which for any given cancer gene may show an absence of genetic mutations, yet reveal epigenetic-based deregulation instead. ${ }^{48-51}$
Other epigenetic abnormalities involve regulatory mechanisms only recently discovered. As described above, TET proteins add hydroxyl groups to $5 \mathrm{mC}$ and not only initiate demethylation but also protect against unsolicited methylation. TET proteins have been found to compete with IDH1 for a common cofactor ( $\alpha$-ketoglutarate), which mutant IDH1 uses to produce the 2-hydroxyglutarate metabolite. ${ }^{52}$ This byproduct inhibits TET2, thereby incapacitating the TET-dependent hydroxylating system and allowing methylation to accumulate in IDH1-mutated cancers. This process may contribute to the glioma $\mathrm{CpG}$ island methylator phenotype, ${ }^{53}$ which characterizes GBM subtypes with distinct clinical and molecular features. ${ }^{54}$ Interestingly, $\mathrm{CpG}$ island methylator phenotype-positive phenotypes appear to have better prognosis in brain and breast cancers. ${ }^{54-56}$ TET alterations observed in cancer include fusion transcripts (ie, MLLTET1) as well as inactivating mutations and deletions at the TET2 locus. ${ }^{57}$

Similarly, dysregulation or reprogramming of histone modifications has been observed in cancer. Viral protein binding of transcriptional regulators such as CREBBP/EP300 has been shown to induce hypoacetylation (H3 K18ac1) and subsequent transformation, ${ }^{58,59}$ while global overexpression of the HDAC family has been demonstrated across multiple tumor types..$^{39}$ Moreover, EZH2, a major HMT of the PcG system, is often overexpressed in cancer. ${ }^{60,61}$ The ensuing aberrant silencing of tumor-suppressor genes strongly implicates a causative oncogenic role for $\mathrm{PcG}$ complexes. It appears that as more mechanisms of epigenetic regulation are uncovered, so too are additional means for dysregulation and oncogenesis.

Epigenetic alterations may serve as useful biomarkers for detecting disease and predicting therapeutic efficacy. For example, hypermethylation of GSTP1 (a glutathione $S$-transferase) is found in approximately $85 \%$ of prostate cancer, including prostate intraepithelial neoplasia. ${ }^{62}$ This is not the case in benign hyperplastic prostate tissue, and therefore its detection in blood or biopsied tissue can be used to detect the presence of prostate cancer cells..$^{63,64}$ Similarly, MGMT and MLH1 (DNA mismatch-repair genes) have been demonstrated to undergo epigenetic inactivation in gliomas ${ }^{65}$ and ovarian cancers, ${ }^{66}$ respectively. Though this may facilitate oncogenesis, it can also prevent such malignancies from recovering from DNA damage caused by chemotherapeutic agents. Patients with hypermethylated MGMT or MLH1 phenotypes have accordingly been shown to have superior clinical responses following treatment with certain cytotoxic agents. ${ }^{67}$ 
Normal cells may employ alternative repair schemes to recover in ways that cancer cells cannot.

\section{The clinical utility of epigenetic agents in cancer management}

The malleable and reversible nature of the cancer epigenome presents intriguing opportunities for novel treatments. Several drugs (specifically DNMT and HDAC inhibitors) have already been approved for select indications, and research efforts have resulted in the development of new drugs designed to be more selective and less toxic. Discovery of how tumors adapt epigenetic machinery to their advantage has also improved understanding of how cancers develop chemoresistance to existing drugs. As such, sensitizing resistant tumors with epigenetic agents to restore the impact of conventional drugs has become a major area of investigation.

\section{Targeting DNA methylation}

DNA methyltransferase inhibitors have found the earliest and greatest success as prototypical epigenetic agents. Azacitidine and decitabine were FDA-approved in the mid2000s for treatment of myelodysplastic syndrome (MDS). As nucleoside analogues, they replace cytosine during DNA replication, in the process trapping DNMTs and targeting them for degradation. Despite indiscriminately targeting DNMTs,${ }^{68}$ they were found at low dosages to selectively reactivate gene expression with relatively few side effects. ${ }^{69}$

Landmark phase III trials with MDS patients comparing decitabine or azacitidine with placebo found a response rate up to $30 \%$ that was relatively durable (decitabine, median 10.3 months), including 9\% demonstrating a complete response (Figure 2). ${ }^{70,71}$ Compared to supportive-care patients, however, those treated with decitabine did not have significantly improved delayed time to acute myeloid leukemia (AML) transformation or death. More recent phase III trials analyzing azacitidine for higher-risk or elderly MDS patients, however, have demonstrated improved overall survival. ${ }^{72}$ Besides MDS, DNA methyltransferase inhibitors have also shown some utility for AML. Decitabine, in a number of phase II trials, showed complete responses in $24 \%-52 \%$ of patients, with pronounced benefit for older patients. ${ }^{73,74}$ The main documented toxicities were myelosuppression (including neutropenia and thrombocytopenia), as well as nausea and vomiting.

That a substantial portion of patients benefited to some degree from such demethylating agents, which are quite nonspecific, is somewhat surprising. There is clearly room to improve the efficacy of this class of drug, which will require

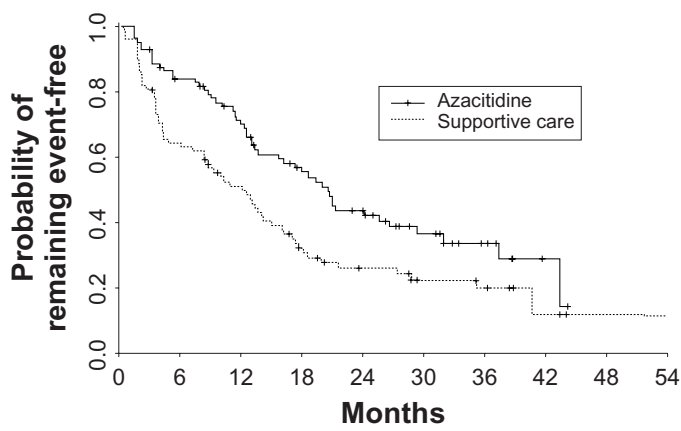

Number of patients at risk

$\begin{array}{lllllllllll}\text { Azacitidine } & 89 & 69 & 55 & 39 & 28 & 16 & 9 & 2 & 0 & 0 \\ \text { Observation } & 82 & 51 & 38 & 22 & 15 & 10 & 8 & 3 & 1 & 1\end{array}$

Figure 2 Kaplan-Meier curves from a trial of azacitidine in patients with myelodysplastic syndrome.

Note: Plot shows time to acute myeloid leukemia transformation or death.

Adapted with permission. @ 2002. American Society of Clinical Oncology. All rights reserved. Silverman LR, Demakos EP, Peterson BL, et al. Randomized controlled trial of azacitidine in patients with the myelodysplastic syndrome: a study of the cancer and leukemia group B. J Clin Oncol. 2002;20(I0):2429-2440.7'

intensive investigation. Potential avenues for improvement include determining the optimal duration of treatment needed and deducing azacitidine's and decitabine's most important molecular effects (key effector genes). ${ }^{69}$ Other priorities include minimizing side effects. Two newer DNMT inhibitors include S110, which releases decitabine intracellularly, ${ }^{75}$ and CP-4200, a derivative of azacitidine with an elaidic acid modification, ${ }^{76}$ have both shown relatively more potent tumoricidal activity in cell lines and mouse models and await clinical investigation. Nanaomycin A, one of the first DNMT3B-specific inhibitors, has been shown to reactivate silenced tumor-suppressor genes. ${ }^{77}$ Results from clinical trials will be needed to determine what incremental benefit, if any, these novel compounds will provide.

\section{Targeting histone acetylation/ deacetylation}

By restoring acetylation to lysine residues on histone tails, HDAC inhibitors counteract the global overexpression of HDACs in cancer and reinstate a more permissive nucleosome structure for transcription. Inhibitors typically target the zincdependent active sites of HDACs, with the exception of class III HDACs (sirtuins), which are $\mathrm{NAD}^{+}$-dependent and do not primarily act on histones. ${ }^{20,78}$ The effects of HDAC inhibitors appear to be to promote $\mathrm{G}_{1}$ or $\mathrm{G}_{2} / \mathrm{M}$ cell-cycle arrest, as well as apoptosis and cell differentiation. Intriguingly, the basis of their efficacy (and toxicity) may not only be limited to histone modification: other reported HDAC targets include p53, signal transducer and activator of transcription 3 , heat shock protein 90, and other important proteins and changing the acetylation status of these may contribute to the biological effects observed..$^{79}$ 
Although there are numerous structural classes of HDAC inhibitors, they can be stratified into broad HDAC inhibitors and class-specific agents. Vorinostat (a panHDAC inhibitor) and romidepsin (a class I HDAC inhibitor) have each shown $>30 \%$ response rates against cutaneous T-cell lymphoma (CTCL) in phase II trials ${ }^{1-4}$ (Figure 3), and accordingly were approved for use by the FDA in the late 2000s. Significant adverse events noted were diarrhea, hypercholesterolemia, and anemia for vorinostat, and nausea, cardiotoxicity, and fatigue for romidepsin. ${ }^{79,80}$ Though generally more tolerable than conventional chemotherapeutic agents, fatigue has been severe enough to cause discontinuation of HDAC inhibitors in up to $30 \%$ of patients.

Nonetheless, enthusiasm continues to build for this class of drug, with more agents in development and undergoing trial than any other class of epigenetic drug. Panobinostat, another pan-HDAC inhibitor, is currently under investigation for numerous hematologic malignancies. A recently reported phase II trial for refractory Hodgkin's lymphoma in 129 patients showed tumor reductions in $74 \%$, with a median duration of response of 6.9 months. ${ }^{81} \mathrm{~A}$ phase III trial with panobinostat and bortezomib is underway for multiple myeloma patients. ${ }^{69}$ Similarly, the multiclass specific HDAC inhibitor mocetinostat (class I and IV) has been studied in phase II trials for refractory Hodgkin's lymphoma, refractory diffuse large B-cell lymphoma, and follicular lymphoma. ${ }^{79,82-84}$ Encouraging results have been seen on preliminary analysis that appear to indicate promise, including a $38 \%$ response rate for Hodgkin's lymphoma patients. ${ }^{82}$ Finally, preclinical studies

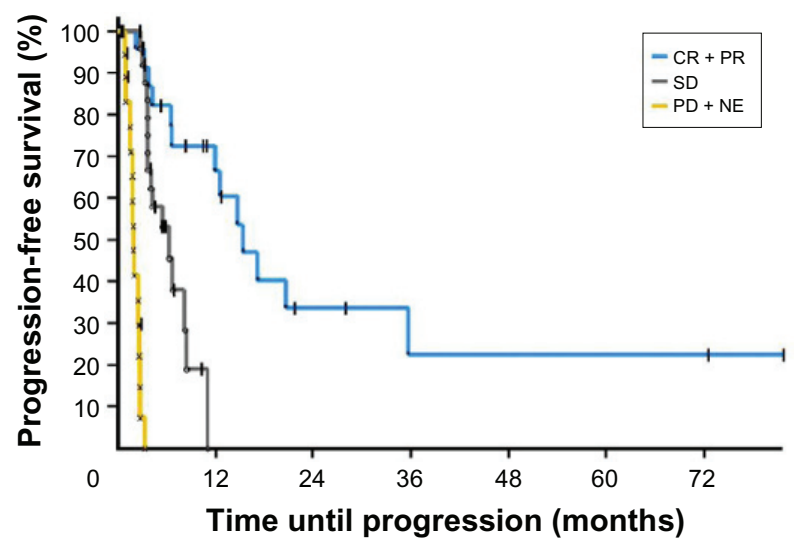

Figure 3 Kaplan-Meier curves from a phase II trial of romidepsin in patients with cutaneous T-cell lymphoma showing progression-free survival of patients with complete response (CR) or partial response (PR), patients with stable disease (SD), and patients with progressive disease (PD) or nonevaluable (NE) patients.

Note: Adapted with permission. (C) 2009. American Society of Clinical Oncology. All rights reserved. Piekarz RL, Frye R, Turner M, et al. Phase II multi-institutional trial of the histone deacetylase inhibitor romidepsin as monotherapy for patients with cutaneous T-cell lymphoma. J Clin Oncol. 2009;27(32): 5410-5417. ${ }^{4}$ show potential for novel compounds such as JQ1 and I-BET, which inhibit bromodomain (BRD)-containing proteins. BRD4, for instance, can bind acetylated histones, leading to proliferation and overexpression by recruitment of the P-TEFb complex or myc. ${ }^{85}$ While known HDAC inhibitors can restore this acetylation, novel compounds such as JQ1 are potentially more specific, as they block contact between BRDs and acetylated histones. ${ }^{86}$ Another synthetic drug called I-BET has also been shown to bind and neutralize the active BRD pocket, competitively reducing BRD4's sequestering activity. ${ }^{87}$ These two drugs demonstrate that targeting transcription factors and epigenetic readers can be a potentially promising avenue to explore.

Paradoxically, HAT inhibitors have also been shown to have some antitumor activity. This contrasts with the global hypoacetylation already seen in many cancers. Naturally occurring drugs such as curcumin, garcinol, and anacardic acid appear to selectively inhibit EP300, CREBBP, or KAT2B, leading to apoptosis or sensitization to therapies such as radiation. ${ }^{88-90}$ As no clinical trials have yet been completed, this class of agents remains largely investigational.

\section{Histone methylation/demethylation}

In contrast to the more global activity of histone acetylation enzymes, HMTs and HDMs can be somewhat more discriminating in the specific amino acid residues they target. ${ }^{84,91}$ This has exciting therapeutic implications, given that elimination of select histone marks could enable more tailored treatment while potentially minimizing side effects. Yet despite the promising nature of these targets, only a few clinically viable compounds have been identified so far, and all currently remain in preclinical levels of study.

Among the first histone demethylases identified was lysine-specific demethylase 1 (LSD1, or KDM1), a flavin adenine dinucleotide-dependent amino oxidase. ${ }^{92}$ By targeting $\mathrm{H} 3 \mathrm{~K} 4 \mathrm{me} 1$ and $\mathrm{H} 3 \mathrm{~K} 4 \mathrm{me} 2$, LSD1 selectively mediates repression and has been found to be overexpressed in a significant number of cancers, including tumors of the brain, breast, and prostate, thereby making it an attractive target for drug therapy. ${ }^{92-94}$ Small molecules such as SL11144 and tranylcypromine appear to be potent inhibitors of LSD1, ${ }^{95,96}$ and have been shown in cancer cell lines to restore expression of multiple aberrantly silenced tumor suppressors, including secreted frizzled-related protein and GATA transcription factors. Research with neuroblastoma xenografts also demonstrates antitumor activity. ${ }^{94}$ However, similar to HDACs, off-target effects on $\mathrm{H} 3 \mathrm{~K} 9 \mathrm{me} 2$ and 
DNMT1 limit its immediate usefulness, ${ }^{97}$ and further study is needed.

The previously mentioned Polycomb group genes also are undergoing active investigation as potential targets. The PRC1 and PRC2 complexes are responsible for H3K27me3mediated repression of transcription. ${ }^{98}$ Such histone marks can lead to DNA methylation and sustained gene silencing. EZH2, a member of the PRC2 complex, is another attractive drug target, given its overexpression in head and neck, breast, and prostate cancers, ${ }^{99}$ and is targeted by a hydrolase inhibitor called 3-deazaneplanocin A (DZNep). By countering EZH2 and inhibiting $\mathrm{H} 3 \mathrm{~K} 27$ trimethylation, DZNep has been shown to induce differentiation as well as apoptosis in cancer cell lines and xenografts, ${ }^{100,101}$ while sparing normal cells. This apparently selective reversal of PRC2-mediated gene repression constitutes a novel treatment approach, and results from clinical trials are forthcoming. However, cancer-mutation surveys have shown that EZH2 can act as an oncogene in some cancers, but as a tumor suppressor in others. Therefore, use of EZH2 inhibitors in the clinic can only be implemented after judicious study.

\section{Future developments in epigenetic therapy}

Epigenetically targeted drugs have already become an important part of the clinical armamentarium, and in some refractory conditions are the only drugs with any activity available to patients. Yet initial successes notwithstanding, challenges remain that must be addressed by future studies. These issues involve expanding the therapeutic reach beyond hematologic cancers, identifying the synergistic potential of combination therapy for better patient outcomes, and understanding the mechanistic basis of these agents to narrow drug activity and more precisely target aberrant marks.

One of the main criticisms of epigenetic therapy has been its relatively lower efficacies when tested on solid tumors. ${ }^{79,84}$ This is likely due to the heterogeneity of solid tumor cells, which may make it more difficult for agents to penetrate and less difficult for tumors to develop resistance. This is especially telling with the epigenetic agents already approved for hematologic malignancies like MDS and CTCL. Vorinostat has been tested as a single agent in head and neck, breast, colorectal, and prostate cancer trials, ${ }^{102-104}$ and has not shown efficacy. A phase II trial with 94 non-small-cell lung cancer patients did not show significantly improved progression-free or overall survival, with $41 \%$ of patients unable to complete the six-cycle regimen. ${ }^{105}$ Similarly, phase I and II trials testing romidepsin (approved for CTCL) showed very marginal clinical improvement when treating refractory solid malignancies, including kidney, prostate, and lung. 5,6,106 Unfortunately, testing epigenetic agents against refractory tumors that have become resistant to other first-line therapies increases the likelihood of failure. Furthermore, it will be important to properly select patients using molecular criteria in future trials, as these features are likely to influence heavily the likelihood of response.

Future trials will likely test combination therapies, with the hypothesis that epigenetic agents may enhance sensitivity to conventional drugs (eg, platinum or taxane chemotherapy) that have known activity. By relaxing chromatin with HDAC inhibitors, it is believed that strands are better exposed to DNA intercalation or genotoxic damage. ${ }^{84}$ Such synergistic combinations are also under intense study to demonstrate reversal of chemoresistance due to epigenetic adaptation, crucial for treating disease that is recurrent or refractory to first-line treatment. Other strategies are examining the role of dual epigenetic therapies, such as DNMT inhibitors with HDAC inhibitors. ${ }^{107,108}$ Given previous experience with azacitidine, it will be essential to master the optimal timing (ie, sequential versus simultaneous) and dosage needed for these cocktails to be effective.

Finally, the advent of next-generation sequencing technologies has made high-throughput mutational and epigenetic analysis accessible and will ultimately allow investigators to paint a more comprehensive portrait of the determinants of response to epigenetically targeted therapies. This will greatly assist in deciphering the many nonhistone and nonpromoter effects observed in many epigenetic agents, including interactivity with miRNAs and kinases. Such large-scale analyses are already under way in mapping cancer genomes via the Cancer Genome Atlas and the International Cancer Genome Consortium. CHIP-seq, whole genome/exome sequencing, RNA-seq, and reversephase protein arrays, as well as the bioinformatic expertise necessary to synthesize them, have all helped make rapid strides possible. ${ }^{109-111}$ Epigenetic analyses of tumors have already demonstrated clinical utility, as demonstrated by the prognostic and predictive use of MGMT methylation status in GBM. ${ }^{112}$ These new tools should lead to substantial improvements in finding reliable biomarkers and selecting the right drugs for the right patient.

\section{Conclusion}

With more than 100 epigenetic agents currently under investigation and a handful already approved in the last decade alone, it is clear that epigenetic therapy will continue 
to impact the management of cancer patients significantly. Such agents are unlikely to be a universal remedy, but their potential to prolong meaningful life and originate new avenues of treatment remains tantalizing. Much remains to be defined about the epigenome regarding its role and its dysregulation in cancer. The widespread presence of mutations in epigenetic regulators in human cancers suggests that the continued efforts in developing strategies to target epigenetic aberrations may contribute to improving efficacy of cancer management.

\section{Disclosure}

The authors report no conflicts of interest in this work.

\section{References}

1. Olsen EA, Kim YH, Kuzel TM, et al. Phase IIb multicenter trial of vorinostat in patients with persistent, progressive, or treatment refractory cutaneous T-cell lymphoma. J Clin Oncol. 2007;25(21):3109-3115.

2. Duvic M, Talpur R, Ni X, et al. Phase 2 trial of oral vorinostat (suberoylanilide hydroxamic acid, SAHA) for refractory cutaneous T-cell lymphoma (CTCL). Blood. 2007;109(1):31-39.

3. Whittaker SJ, Demierre MF, Kim EJ, et al. Final results from a multicenter, international, pivotal study of romidepsin in refractory cutaneous T-cell lymphoma. J Clin Oncol. 2010;28(29):4485-4491.

4. Piekarz RL, Frye R, Turner M, et al. Phase II multi-institutional trial of the histone deacetylase inhibitor romidepsin as monotherapy for patients with cutaneous T-cell lymphoma. J Clin Oncol. 2009;27(32): 5410-5417.

5. Schrump DS, Fischette MR, Nguyen DM, et al. Clinical and molecular responses in lung cancer patients receiving romidepsin. Clin Cancer Res. 2008;14(1):188-198.

6. Molife LR, Attard G, Fong PC, et al. Phase II, two-stage, single-arm trial of the histone deacetylase inhibitor (HDACi) romidepsin in metastatic castration-resistant prostate cancer (CRPC). Ann Oncol. 2010;21(1): 109-113.

7. Bauman J, Verschraegen C, Belinsky S, et al. A phase I study of 5 -azacytidine and erlotinib in advanced solid tumor malignancies. Cancer Chemother Pharmacol. 2012;69(2):547-554.

8. Eden A, Gaudet F, Waghmare A, Jaenisch R. Chromosomal instability and tumors promoted by DNA hypomethylation. Science. 2003;300(5618):455.

9. Wang Y, Leung FC. An evaluation of new criteria for $\mathrm{CpG}$ islands in the human genome as gene markers. Bioinformatics. 2004;20(7): $1170-1177$.

10. Irizarry RA, Ladd-Acosta C, Wen B, et al. The human colon cancer methylome shows similar hypo- and hypermethylation at conserved tissue-specific CpG island shores. Nat Genet. 2009;41(2):178-186.

11. Varambally S, Cao Q, Mani RS, et al. Genomic loss of microRNA-101 leads to overexpression of histone methyltransferase EZH2 in cancer. Science. 2008;322(5908):1695-1699.

12. Guenther MG, Levine SS, Boyer LA, Jaenisch R, Young RA. A chromatin landmark and transcription initiation at most promoters in human cells. Cell. 2007;130(1):77-88.

13. Bird A. DNA methylation patterns and epigenetic memory. Genes Dev. 2002;16(1):6-21.

14. Endres M, Fan G, Meisel A, Dirnagl U, Jaenisch R. Effects of cerebral ischemia in mice lacking DNA methyltransferase 1 in post-mitotic neurons. Neuroreport. 2001;12(17):3763-3766.

15. Gao Q, Steine EJ, Barrasa MI, et al. Deletion of the de novo DNA methyltransferase Dnmt3a promotes lung tumor progression. Proc Natl Acad Sci U S A. 2011;108(44):18061-18066.
16. Nosho K, Shima K, Irahara N, et al. DNMT3B expression might contribute to $\mathrm{CpG}$ island methylator phenotype in colorectal cancer. Clin Cancer Res. 2009;15(11):3663-3671.

17. Linhart HG, Lin H, Yamada Y, et al. Dnmt3b promotes tumorigenesis in vivo by gene-specific de novo methylation and transcriptional silencing. Genes Dev. 2007;21(23):3110-3122.

18. Lister R, Pelizzola M, Dowen RH, et al. Human DNA methylomes at base resolution show widespread epigenomic differences. Nature 2009;462(7271):315-322.

19. Ito S, Shen L, Dai Q, et al. Tet proteins can convert 5-methylcytosine to 5-formylcytosine and 5-carboxylcytosine. Science. 2011;333(6047): 1300-1303.

20. Rodriguez-Paredes M, Esteller M. Cancer epigenetics reaches mainstream oncology. Nat Med. 2011;17(3):330-339.

21. Campos EI, Reinberg D. Histones: annotating chromatin. Annu Rev Genet. 2009;43:559-599.

22. Beck DB, Bonasio R, Kaneko S, et al. Chromatin in the nuclear landscape. Cold Spring Harb Symp Quant Biol. 2011;75:11-22.

23. Sawan C, Herceg Z. Histone modifications and cancer. Adv Genet. 2010;70:57-85.

24. Barski A, Cuddapah S, Cui K, et al. High-resolution profiling of histone methylations in the human genome. Cell. 2007;129(4):823-837.

25. Rosenfeld JA, Wang Z, Schones DE, Zhao K, DeSalle R, Zhang MQ. Determination of enriched histone modifications in non-genic portions of the human genome. BMC Genomics. 2009;10:143.

26. Li B, Carey M, Workman JL. The role of chromatin during transcription. Cell. 2007;128(4):707-719.

27. Hu G, Cui K, Northrup D, et al. H2A.Z facilitates access of active and repressive complexes to chromatin in embryonic stem cell self-renewal and differentiation. Cell Stem Cell. 2013;12(2):180-192.

28. Heintzman ND, Hon GC, Hawkins RD, et al. Histone modifications at human enhancers reflect global cell-type-specific gene expression. Nature. 2009;459(7243):108-112.

29. Gaffney DJ, McVicker G, PaiAA, et al. Controls of nucleosome positioning in the human genome. PLoS Genet. 2012;8(11):e1003036.

30. Baylin SB, Jones PA. A decade of exploring the cancer epigenome biological and translational implications. Nat Rev Cancer. 2011;11(10): 726-734.

31. Wen B, Wu H, Loh YH, Briem E, Daley GQ, Feinberg AP. Euchromatin islands in large heterochromatin domains are enriched for CTCF binding and differentially DNA-methylated regions. BMC Genomics. 2012;13:566.

32. Keller C, Adaixo R, Stunnenberg R, Woolcock KJ, Hiller S, Buhler M. HP1(Swi6) mediates the recognition and destruction of heterochromatic RNA transcripts. Mol Cell. 2012;47(2):215-227.

33. Fujimura $\mathrm{Y}$, Isono K, Vidal M, et al. Distinct roles of Polycomb group gene products in transcriptionally repressed and active domains of Hoxb8. Development. 2006;133(12):2371-2381.

34. Asangani IA, Ateeq B, Cao Q, et al. Characterization of the EZH2MMSET histone methyltransferase regulatory axis in cancer. Mol Cell. 2013;49(1):80-93.

35. Banerjee R, Mani RS, Russo N, et al. The tumor suppressor gene rap1GAP is silenced by miR-101-mediated EZH2 overexpression in invasive squamous cell carcinoma. Oncogene. 2011;30(42):4339-4349.

36. Sakurai T, Bilim VN, Ugolkov AV, et al. The enhancer of zeste homolog 2 (EZH2), a potential therapeutic target, is regulated by miR-101 in renal cancer cells. Biochem Biophys Res Commun. 2012;422(4):607-614.

37. Esteller M. Epigenetics in cancer. $N$ Engl J Med. 2008;358(11): 1148-1159.

38. Feinberg AP. Cancer epigenetics is no Mickey Mouse. Cancer Cell. 2005;8(4):267-268.

39. Fraga MF, Ballestar E, Villar-Garea A, et al. Loss of acetylation at Lys 16 and trimethylation at Lys 20 of histone $\mathrm{H} 4$ is a common hallmark of human cancer. Nat Genet. 2005;37(4):391-400.

40. Seligson DB, Horvath S, Shi T, et al. Global histone modification patterns predict risk of prostate cancer recurrence. Nature. 2005;435(7046): 1262-1266. 
41. You JS, Jones PA. Cancer genetics and epigenetics: two sides of the same coin? Cancer Cell. 2012;22(1):9-20.

42. Dawson MA, Kouzarides T, Huntly BJ. Targeting epigenetic readers in cancer. N Engl J Med. 2012;367(7):647-657.

43. Ley TJ, Ding L, Walter MJ, et al. DNMT3A mutations in acute myeloid leukemia. N Engl J Med. 2010;363(25):2424-2433.

44. Jones PA, Baylin SB. The epigenomics of cancer. Cell. 2007;128(4): 683-692.

45. Iwama A, Oguro H, Negishi M, et al. Enhanced self-renewal of hematopoietic stem cells mediated by the polycomb gene product Bmi-1. Immunity. 2004;21(6):843-851.

46. Jacobs JJ, Kieboom K, Marino S, DePinho RA, van Lohuizen M. The oncogene and Polycomb-group gene bmi-1 regulates cell proliferation and senescence through the ink4a locus. Nature. 1999;397(6715): 164-168.

47. Jones PA, Baylin SB. The fundamental role of epigenetic events in cancer. Nat Rev Genet. 2002;3(6):415-428.

48. Cancer Genome Atlas Network. Comprehensive molecular portraits of human breast tumours. Nature. 2012;490(7418):61-70.

49. Cancer Genome Atlas Network. Comprehensive molecular characterization of human colon and rectal cancer. Nature. 2012; 487(7407):330-337.

50. Cancer Genome Atlas Research Network. Integrated genomic analyses of ovarian carcinoma. Nature. 2011;474(7353):609-615.

51. Cancer Genome Atlas Research N. Comprehensive genomic characterization of squamous cell lung cancers. Nature. 2012;489(7417): 519-525.

52. Figueroa ME, Abdel-Wahab O, Lu C, et al. Leukemic IDH1 and IDH2 mutations result in a hypermethylation phenotype, disrupt TET2 function, and impair hematopoietic differentiation. Cancer Cell. 2010;18(6):553-567.

53. Issa JP. CpG island methylator phenotype in cancer. Nat Rev Cancer. 2004;4(12):988-993.

54. Turcan S, Rohle D, Goenka A, et al. IDH1 mutation is sufficient to establish the glioma hypermethylator phenotype. Nature. 2012;483(7390):479-483.

55. Fang F, Turcan S, Rimner A, et al. Breast cancer methylomes establish an epigenomic foundation for metastasis. Sci Transl Med. 2011;3(75): $75 \mathrm{ra} 25$.

56. van den Bent MJ, Gravendeel LA, Gorlia T, et al. A hypermethylated phenotype is a better predictor of survival than MGMT methylation in anaplastic oligodendroglial brain tumors: a report from EORTC study 26951. Clin Cancer Res. 2011;17(22):7148-7155.

57. Delhommeau F, Dupont S, Della Valle V, et al. Mutation in TET2 in myeloid cancers. $N$ Engl J Med. 2009;360(22):2289-2301.

58. Ferrari R, Pellegrini M, Horwitz GA, Xie W, Berk AJ, Kurdistani SK. Epigenetic reprogramming by adenovirus e1a. Science. 2008;321(5892):1086-1088.

59. Rasti M, Grand RJ, Mymryk JS, Gallimore PH, Turnell AS. Recruitment of $\mathrm{CBP} / \mathrm{p} 300$, TATA-binding protein, and $\mathrm{S} 8$ to distinct regions at the $\mathrm{N}$ terminus of adenovirus E1A. $J$ Virol. 2005;79(9): 5594-5605.

60. Cao P, Deng Z, Wan M, et al. MicroRNA-101 negatively regulates Ezh2 and its expression is modulated by androgen receptor and HIF-1alpha/ HIF-1beta. Mol Cancer. 2010;9:108.

61. Smits M, Nilsson J, Mir SE, et al. miR-101 is down-regulated in glioblastoma resulting in EZH2-induced proliferation, migration, and angiogenesis. Oncotarget. 2010;1(8):710-720.

62. Jeronimo C, Henrique R, Hoque MO, et al. A quantitative promoter methylation profile of prostate cancer. Clin Cancer Res. 2004;10(24): 8472-8478.

63. Brooks JD, Weinstein M, Lin X, et al. CG island methylation changes near the GSTP1 gene in prostatic intraepithelial neoplasia. Cancer Epidemiol Biomarkers Prev. 1998;7(6):531-536.

64. Henrique R, Jeronimo C. Molecular detection of prostate cancer: a role for GSTP1 hypermethylation. Eur Urol. 2004;46(5):660-669; discussion 669.
65. Esteller M, Garcia-Foncillas J, Andion E, et al. Inactivation of the DNA-repair gene MGMT and the clinical response of gliomas to alkylating agents. $N$ Engl J Med. 2000;343(19):1350-1354.

66. Plumb JA, Strathdee G, Sludden J, Kaye SB, Brown R. Reversal of drug resistance in human tumor xenografts by $2^{\prime}$-deoxy-5-azacytidineinduced demethylation of the hMLH1 gene promoter. Cancer Res. 2000;60(21):6039-6044.

67. Baylin SB, Ohm JE. Epigenetic gene silencing in cancera mechanism for early oncogenic pathway addiction? Nat Rev Cancer. 2006;6(2):107-116.

68. Schneider-Stock R, Diab-Assef M, Rohrbeck A, et al. 5-Aza-cytidine is a potent inhibitor of DNA methyltransferase $3 \mathrm{a}$ and induces apoptosis in HCT-116 colon cancer cells via Gadd45- and p53-dependent mechanisms. J Pharmacol Exp Ther. 2005;312(2):525-536.

69. Kelly TK, De Carvalho DD, Jones PA. Epigenetic modifications as therapeutic targets. Nat Biotechnol. 2010;28(10):1069-1078.

70. Kantarjian H, Issa JP, Rosenfeld CS, et al. Decitabine improves patient outcomes in myelodysplastic syndromes: results of a phase III randomized study. Cancer. 2006;106(8):1794-1803.

71. Silverman LR, Demakos EP, Peterson BL, et al. Randomized controlled trial of azacitidine in patients with the myelodysplastic syndrome: a study of the cancer and leukemia group B. J Clin Oncol. 2002;20(10):2429-2440.

72. Fenaux P, Mufti GJ, Hellstrom-Lindberg E, et al. Efficacy of azacitidine compared with that of conventional care regimens in the treatment of higher-risk myelodysplastic syndromes: a randomised, open-label, phase III study. Lancet Oncol. 2009;10(3):223-232.

73. Blum W, Garzon R, Klisovic RB, et al. Clinical response and miR-29b predictive significance in older AML patients treated with a 10-day schedule of decitabine. Proc Natl Acad Sci U S A. 2010;107(16):7473-7478.

74. Cashen AF, Schiller GJ, O'Donnell MR, DiPersio JF. Multicenter, phase II study of decitabine for the first-line treatment of older patients with acute myeloid leukemia. J Clin Oncol. 2010;28(4): 556-561.

75. Yoo CB, Jeong S, Egger G, et al. Delivery of 5-aza-2'-deoxycytidine to cells using oligodeoxynucleotides. Cancer Res. 2007;67(13): 6400-6408.

76. Brueckner B, Rius M, Markelova MR, et al. Delivery of 5-azacytidine to human cancer cells by elaidic acid esterification increases therapeutic drug efficacy. Mol Cancer Ther. 2010;9(5):1256-1264.

77. Kuck D, Caulfield T, Lyko F, Medina-Franco JL. Nanaomycin A selectively inhibits DNMT3B and reactivates silenced tumor suppressor genes in human cancer cells. Mol Cancer Ther. 2010;9(11): 3015-3023.

78. Saunders LR, Verdin E. Sirtuins: critical regulators at the crossroads between cancer and aging. Oncogene. 2007;26(37):5489-5504.

79. Federico M, Bagella L. Histone deacetylase inhibitors in the treatment of hematological malignancies and solid tumors. J Biomed Biotechnol. 2011;2011:475641.

80. Lane AA, Chabner BA. Histone deacetylase inhibitors in cancer therapy. J Clin Oncol. 2009;27(32):5459-5468.

81. Younes A, Sureda A, Ben-Yehuda D, et al. Panobinostat in patients with relapsed/refractory Hodgkin's lymphoma after autologous stem-cell transplantation: results of a phase II study. J Clin Oncol. 2012;30(18): 2197-2203.

82. Younes A, Oki Y, Bociek RG, et al. Mocetinostat for relapsed classical Hodgkin's lymphoma: an open-label, single-arm, phase 2 trial. Lancet Oncol. 2011;12(13):1222-1228.

83. Garcia-Manero G, Assouline S, Cortes J, et al. Phase 1 study of the oral isotype specific histone deacetylase inhibitor MGCD0103 in leukemia. Blood. 2008;112(4):981-989.

84. Mack GS. To selectivity and beyond. Nat Biotechnol. 2010;28(12): 1259-1266.

85. Yang Z, He N, Zhou Q. Brd4 recruits P-TEFb to chromosomes at late mitosis to promote $\mathrm{G} 1$ gene expression and cell cycle progression. Mol Cell Biol. 2008;28(3):967-976. 
86. Filippakopoulos P, Qi J, Picaud S, et al. Selective inhibition of BET bromodomains. Nature. 2010;468(7327):1067-1073.

87. Nicodeme E, Jeffrey KL, Schaefer U, et al. Suppression of inflammation by a synthetic histone mimic. Nature. 2010;468(7327):1119-1123.

88. Balasubramanyam K, Varier RA, Altaf M, et al. Curcumin, a novel p300/CREB-binding protein-specific inhibitor of acetyltransferase, represses the acetylation of histone/nonhistone proteins and histone acetyltransferase-dependent chromatin transcription. $J$ Biol Chem. 2004;279(49):51163-51171.

89. Balasubramanyam K, Altaf M, Varier RA, et al. Polyisoprenylated benzophenone, garcinol, a natural histone acetyltransferase inhibitor, represses chromatin transcription and alters global gene expression. $J$ Biol Chem. 2004;279(32):33716-33726.

90. Sun Y, Jiang X, Chen S, Price BD. Inhibition of histone acetyltransferase activity by anacardic acid sensitizes tumor cells to ionizing radiation. FEBS Lett. 2006;580(18):4353-4356.

91. Lall S. Primers on chromatin. Nat Struct Mol Biol. 2007;14(11): $1110-1115$.

92. Metzger E, Wissmann M, Yin N, et al. LSD1 demethylates repressive histone marks to promote androgen-receptor-dependent transcription. Nature. 2005;437(7057):436-439.

93. Lim S, Janzer A, Becker A, et al. Lysine-specific demethylase 1 (LSD1) is highly expressed in ER-negative breast cancers and a biomarker predicting aggressive biology. Carcinogenesis. 2010;31(3): 512-520.

94. Schulte JH, Lim S, Schramm A, et al. Lysine-specific demethylase 1 is strongly expressed in poorly differentiated neuroblastoma: implications for therapy. Cancer Res. 2009;69(5):2065-2071.

95. Huang Y, Stewart TM, Wu Y, et al. Novel oligoamine analogues inhibit lysine-specific demethylase 1 and induce reexpression of epigenetically silenced genes. Clin Cancer Res. 2009;15(23):7217-7228.

96. Wu Y, Steinbergs N, Murray-Stewart T, Marton LJ, Casero RA. Oligoamine analogues in combination with 2-difluoromethylornithine synergistically induce re-expression of aberrantly silenced tumoursuppressor genes. Biochem J. 2012;442(3):693-701.

97. Wang J, Hevi S, Kurash JK, et al. The lysine demethylase LSD1 (KDM1) is required for maintenance of global DNA methylation. Nat Genet. 2009;41(1):125-129.

98. Bracken AP, Dietrich N, Pasini D, Hansen KH, Helin K. Genome-wide mapping of Polycomb target genes unravels their roles in cell fate transitions. Genes Dev. 2006;20(9):1123-1136.

99. Albert M, Helin K. Histone methyltransferases in cancer. Semin Cell Dev Biol. 2010;21(2):209-220.

100. Gannon O, Endo-Munoz LB, Merida de Long L, Hazar-Rethinam M, Saunders NA. Dysregulation of the repressive H3K27 trimethylation mark in head and neck squamous cell carcinoma contributes to dysregulated squamous differentiation. Clin Cancer Res. 2013;19(2):428-441.
101. Tan J, Yang X, Zhuang L, et al. Pharmacologic disruption of Polycombrepressive complex 2-mediated gene repression selectively induces apoptosis in cancer cells. Genes Dev. 2007;21(9):1050-1063.

102. Bradley D, Rathkopf D, Dunn R, et al. Vorinostat in advanced prostate cancer patients progressing on prior chemotherapy (National Cancer Institute Trial 6862): trial results and interleukin-6 analysis: a study by the Department of Defense Prostate Cancer Clinical Trial Consortium and University of Chicago Phase 2 Consortium. Cancer. 2009;115(23):5541-5549.

103. Vansteenkiste J, Van Cutsem E, Dumez H, et al. Early phase II trial of oral vorinostat in relapsed or refractory breast, colorectal, or nonsmall cell lung cancer. Invest New Drugs. 2008;26(5):483-488.

104. Blumenschein GR Jr, Kies MS, Papadimitrakopoulou VA, et al. Phase II trial of the histone deacetylase inhibitor vorinostat (Zolinza, suberoylanilide hydroxamic acid, SAHA) in patients with recurrent and/or metastatic head and neck cancer. Invest New Drugs. 2008;26(1):81-87.

105. Ramalingam SS, Maitland ML, Frankel P, et al. Carboplatin and Paclitaxel in combination with either vorinostat or placebo for firstline therapy of advanced non-small-cell lung cancer. J Clin Oncol. 2010;28(1):56-62.

106. Stadler WM, Margolin K, Ferber S, McCulloch W, Thompson JA. A phase II study of depsipeptide in refractory metastatic renal cell cancer. Clin Genitourin Cancer. 2006;5(1):57-60.

107. Gorgun G, Calabrese E, Hideshima T, et al. A novel Aurora-A kinase inhibitor MLN8237 induces cytotoxicity and cell-cycle arrest in multiple myeloma. Blood. 2010;115(25):5202-5213.

108. den Hollander J, Rimpi S, Doherty JR, et al. Aurora kinases A and B are up-regulated by Myc and are essential for maintenance of the malignant state. Blood. 2010;116(9):1498-1505.

109. Martin JA, Wang Z. Next-generation transcriptome assembly. Nat Rev Genet. 2011;12(10):671-682.

110. Furey TS. ChIP-seq and beyond: new and improved methodologies to detect and characterize protein-DNA interactions. Nat Rev Genet. 2012;13(12):840-852.

111. Wong KM, Hudson TJ, McPherson JD. Unraveling the genetics of cancer: genome sequencing and beyond. Аппи Rev Genomics Hum Genet. 2011;12:407-430.

112. Hegi ME, Diserens AC, Gorlia T, et al. MGMT gene silencing and benefit from temozolomide in glioblastoma. $N$ Engl $J$ Med. 2005;352(10):997-1003.
OncoTargets and Therapy

\section{Publish your work in this journal}

OncoTargets and Therapy is an international, peer-reviewed, open access journal focusing on the pathological basis of all cancers, potential targets for therapy and treatment protocols employed to improve the management of cancer patients. The journal also focuses on the impact of management programs and new therapeutic agents and protocols on

\section{Dovepress}

patient perspectives such as quality of life, adherence and satisfaction The manuscript management system is completely online and includes a very quick and fair peer-review system, which is all easy to use. Visit http://www.dovepress.com/testimonials.php to read real quotes from published authors. 